[LONDON] A meeting of signatory states to the United Nations biodiversity convention ended in Bratislava, Slovakia, last week with agreement on a compromise over whether the convention should be provided with independent scientific advice.

The meeting agreed to set up expert panels by 2000 on marine biodiversity, and inland water biodiversity. A working group to establish guidelines on bioprospecting will be set up immediately (see Nature 392, 535-540; 1998).

But the panels will not be totally independent. The bioprospecting group will be appointed directly by governments. Members of the other expert panels will be picked by the convention's executive secretary from shortlists from each of the convention's five regions: Africa, Asia, Latin America, Eastern Europe and Western Europe.

The convention's 'parties' also agreed to strengthen its formal body of governmentappointed scientists, which will meet twice before the next biodiversity conference in 2000, instead of just once. And the Australian government agreed to help find ways of increasing the availability of taxonomy expertise, particularly in developing countries.

The convention's budget was increased by a modest 7.5 per cent to US\$8.6 million.
And a deadline of February 1999 was set to finalize the protocol regulating the safety of genetically modified organisms.

The agreement on expert panels amounts to a compromise between developed and advanced developing country parties on the one hand, and least developing country parties on the other.

The former had proposed setting up panels of scientists from outside the convention to advise it on scientific issues related to biodiversity. These governments favoured such independent expertise on the grounds that the convention's existing advisory body met too infrequently.

They also argued that this body is unable to offer practical advice, given that the views of its member scientists tend to reflect the policies of their governments.

But decisions at UN conventions need a consensus of all the parties. And the least developed countries had signalled their opposition to extra scientific advice in the conference's first week (see Nature 393, 99; 1998). They were concerned that they would not have sufficient control over the new science panels, particularly if they were dominated by scientists from developed countries.

The decision to set up a group to formulate guidelines on bioprospecting stems from continued controversy over access to genetic resources. It will be welcomed, in particular, by pharmaceutical companies, which are increasingly concerned at what they perceive to be a trend in developing countries to pass tough laws regulating such companies, and other research organizations, when prospecting for natural products.

Under a Philippines law, for example, all scientists - whether local or from abroad — must seek permission directly from local communities before prospecting for natural products. At least two companies, Glaxo Wellcome and Novo Nordisk, have said they will cut back on research on natural products if other countries follow suit.

The bioprospecting working group will also look into the issue of intellectual property rights. Some developing countries, led by Ethiopia, had wanted a firm statement on perceived inconsistencies between the traderelated aspects of intellectual property rights under the World Trade Organization (WTO) rules, and under the biodiversity convention.

The convention calls for intellectual property rights regulations to recognize the contributions of, for example, traditional healers in the development of drugs from natural products. But this is not the case under WTO rules.

EhsanMasood

\title{
Japan's quake strategy urged to switch to long-term forecasting
}

[токуо] Earthquake research in Japan should aim at making 10-year forecasts of locations likely to be struck by major tremors, a group of 160 seismologists has recommended.

The proposal, part of a new research plan drawn up by the Japanese seismologists, represents a break from the previous policy, which has focused on short-term prediction of the location and size of earthquakes likely to occur within a few days.

The new plan is expected to serve as the backbone for the latest earthquakeprediction strategy being drafted by the Geodetic Council, an advisory body to the Ministry of Education, Science, Sports and Culture (Monbusho).

According to Yozo Hamano, leader of the earthquake researchers' group and a professor of Earth dynamics at Tokyo University, the ad hoc group was formed last year in response to a government report on earthquake prediction.

Subcommittees of the Geodetic Council had compiled a report last June which admitted that the short-term prediction of earthquakes - a programme that receives an annual budget of more than $¥ 20$ billion (US\$149 million) —is extremely difficult, and that there is a huge gap between the public's perception of the ability to predict

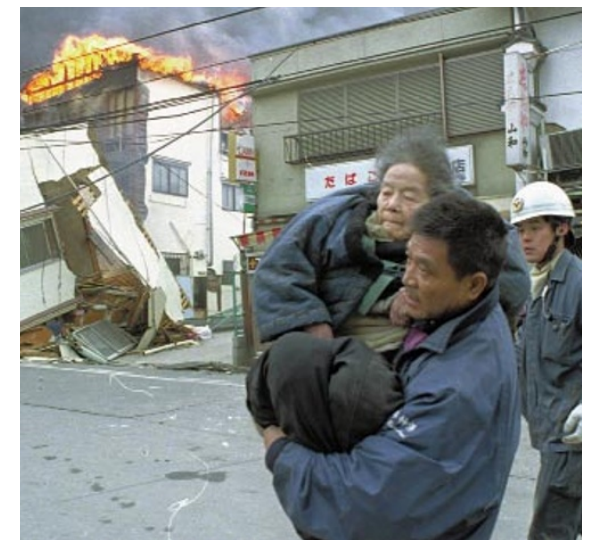

Tremor terrors: longer forecasts would aim to give more warning of quakes than Kobe had in 1995.

earthquakes and the actual performance of science (see Nature 388, 4; 1997).

The new plan, with its long-term strategy, would mark the first change in the 30-year-old programme, which has been focusing mainly on predicting imminent earthquakes in the Tokai region, southwest of Tokyo.

According to Hamano, the new approach emphasizes elucidating a quake plan for the whole Japanese archipelago, through specifying the regions that have crustal distortions and are likely to experience an earthquake. "Thirty years of research in earthquake prediction has helped collect data for building new research methods," says Hamano. "Recent improvement in observational methods, for example global positioning systems and other space-based techniques, are also encouraging for the new earthquake-prediction programme."

But critics of the prediction programme are sceptical about the scientific basis of the plan, as well as its claim that it would bring changes to the existing programme. The main focus of the programme will see a shift towards long-term forecasts. But research in short-term prediction is still widely supported, and is likely to persist on a smaller scale in the eighth five-year prediction plan, which begins next year.

Robert Geller, a seismologist at Tokyo University, points out that the proposed plan lacks adequate theory or method required for making the reliable forecasts that it claims are possible.

"Accurate earthquake prediction is impossible, and will be for the foreseeable future," says Geller. "What's needed is basic research on the earthquake-source process, rather than a national project aimed at issuing predictions." 